\title{
EDUCATIONAL PROSPECTS OF THE PRACTICAL SOLUTION OF PERSONAL ONTOLOGICAL INSECURITY
}

\author{
Nadiya Hapon \\ Doctor of Philosophy, Professor, Ivan Franko National University of Lviv, Ukraine \\ e-mail: Nadiya.Hapon@lnu.edu.ua,orcid.org/0000-0002-8699-2420
}

\section{Summary}

The article considered the problem of ontological insecurity of man and the optimal educational options for its solution. The history of the concept of "ontological insecurity" in the works of R. D. Laing, A. Giddens and J. Young was considered. It is revealed that the ontological insecurity of a person is caused by macrosocial factors (migration, war, pandemic, social crisis). Adverse communication and family relationships are microsocial factors in person's ontological insecurity. The separate directions of psychotherapy of the ontologically insecure person were analyzed. The author considered possibilities of psychotherapeutic intervention in the correction of psychological consequences of staying in distorted family systems (M. Bowen). Family therapy, based on Bowen's theory, aims at increasing the level of differentiation of the self in the client's emotional system, leading to a decrease in the manifestations of somatic, psychological or social symptoms. In the 1970-80s, family psychotherapy was embraced by the process of changing orientation from psychoanalysis and behaviorism to a more cognitive model. The study found that the solution of the problem of ontological insecurity of the person lies in the plane of realization of educational, psychological educational programs. Work to reduce ontological insecurity can be carried out by psychological services of educational institutions, which offer free assistance (trainings, consultations) with elements of individual and family therapy to all participants in the educational system.

Keywords: micro- and macrosocial factors, family system, relationships, communication, psychotherapy.

DOI: https://doi.org/10.23856/4404

\section{Introduction}

The rationally organized social life, based on laws and regulation of social behavior and development of individual and community prosocial activity has great educational importance. Such social life of individuals ensures predictability, conflict-free and sustainable community and state as a whole. Educational tasks of organization and regulation of social life are aimed to reduce the risks of disorganization of society, play a prevention role in the occurrence of social fears, support human ontological safety. However, in society, during its crisis periods (economic, financial, war, forced resettlement of individuals, etc.), spontaneous processes characterized by certain instability, uncontrolled relations are always increasing. Actually spontaneous processes, formation of volatility zones, common uncertainty in society is a threat to the ontological safety of people, and therefore an important problem of educational institutions. Ontological safety as a sense of security, is formed in the conditions of interaction of the individual with institutions (family, school, college, university, professional activity). Therefore, ontological safety is based on institutionality, on the system of status, role-playing interactions between individuals. It is appropriate to distinguish micro- and macro-social levels at which 
ontological security may be weakened. At the microsocial level, such zones of volatility include crisis situations in social relations.

Many authors have addressed ontological insecurity as an analytical category at different times, in particular well-known researchers: psychiatrist of existential-phenomenological direction R. D. Laing (Laing, 1960) sociologists A. Giddens (Giddens, 1999), J. Young (Young, 2007). The problem of codependency and its possible solutions have been considered in the context of family psychotherapy (works by G. Bateson, M. Bateson, M. M. Bowen, R. Laing, M. H. Erickson, L. Hoffman, J. Haley, V. Satir, C. Whitaker, S. Minukhin, S. M. Palazzoli, D. Jackson, J. Weakland and others). The problem of loss of ontological security is relevant for the modern educational system. The aim of the study is to justify the need for a broad socio-psychological approach to solving the problem of ontological insecurity in families with communication dysfunction and interdependence of its members. The objectives of the article are to define the concept of "ontological insecurity", to consider the discursive history of the concept, to analyze the psychological experience of overcoming ontological insecurity in family psychotherapy.

\section{The concept of personal ontological security}

At the macro-social level, it is appropriate to distinguish the factors that provoke the occurrence of uncertainty that destroys the basis of ontological safety. Among them are group and intergroup conflicts, war, crisis phenomena in public life, formalization of social relations. The microsocial level of ontological safety allows us to consider the educational and socio-psychological state of personal ontological security. Ontological security arises in conditions of openness, contact and clarity of the world for people. It exists inside everyday reality. An important condition for personal ontological safety is a trust in family members, parents, which has a psychological basis. On the basis of child's trust in the mother a trust in the surrounding reality is formed (E. Erickson, K. Horny). The absence of hostility, anxiety in the process of relationships and personal interaction with social institutions is similar to the psychological child's trust in the mother. Sociological research show that the level of trust in the institutions of society correlates with the level of fear. The lower is trust in social centers, institutions, in particular educational institutions, the higher is the level of anxiety and fear (Giddens, 1999). Therefore, the integrity and wholeness of the modern person can be threatened by various alienated social relations, indifference, disrespect of educational social institutions to the personal and family problems and psychological crises. This is how the society of disparate individuals is exposed. Such society has a number of problems, among which the educational problem of personal ontological insecurity and its overcoming has to be solved (Young, 2007).

Only a harmonized self gives a person the sense of presence in the world as real, living, holistic, and continuous (in a timely sense). The outer (social) world, other people are experienced while equally real, continuous, holistic. Actually, this experience characterizes an "ontologically secure person" (Laing, 1960: 63). The concept of ontological security - "ontological security" (translation options: ontological confidence, ontological safety) was generally outlined by the existential psychiatrist R. Laing as polar, different from the ontological insecurity of schizoids and schizophrenics, which constituted the subject of his study (Laing, 1960).

The existential position of security-insecurity corresponds to the degree of reliability of basic elements of being-in-the-world structuring: I (mental I and the body) and non-I (other people, the world). The outlined existential provisions are specified by another opposition to basic existential settings - embodied and unembodied self). The embodiment of mental I in 
body as a physical object, the identification of one's own body (in time and space) continues the integrity of person in his life-in-the-world (this is the embodiment in existential sense).

Instead, instability corresponds to alienation from self and others, and the splits of being in the world. Existential positions of confidence, incarnation, insecurity, find expression in ontological feelings that describe all the diversity of human experiences of themselves and the world. A sense of ontological security allows a person to face social, spiritual, ethical or welcome obstacles painlessly. Ontological security gives a person a sense of confidence in their reality and identity, as well as in the reality of the surrounding world and the identities of other people. Unlike attempts to individualize the concept of ontological insecurity, R. Laing (Laing, 1985) revealed it as a pathological experience for the whole society, pointing to a certain responsibility of society for mental disorders.

The integrity, wholeness of a modern person can be threatened by alienated social relations, indifference, disrespect of educational social institutions to the problems and crises of the person and family. This is how the society of disparate individuals is exposed. Such a society has a number of problems, among which the problem of personal ontological insecurity and its overcoming is solved. Only a harmonized self gives a person the sense of presence in the world as real, living, holistic, and continuous (in sense of time). The outer (social) world and other people are experienced as equally real, continuous, holistic. Actually, this experience characterizes an "ontologically secure person" (Laing, 1960: 63). A sense of ontological security allows a person to face social, spiritual, ethical or vital obstacles painlessly. Ontological security gives a person a sense of confidence in their reality and identity, as well as in the reality of the surrounding world, the identities of other people.

The scientist imposes mental illness not into abstract ontology of the world, but - into the ontology of society. The normal state of a person, its adaptability costs a lot for personality, it is a thing of high price, payed to society. A person is forced to pay for his "normality" by the formalization of human relations, indifference, "false consciousness", which allows to enter the system of "social fantasies". At the level of social relations, it can be social stereotypes, prejudices, beliefs, political views. At the level of interpersonal relationships - family and group myths. A person who tries to get out of the group fantasy system poses an existential threat to other members of the group because he questions their beliefs and therefore affects their lifestyle. Such people are usually branded by the group with the label of insanity; the group has to protect itself from their influence. As Laing points out, experts in the field of psychiatry call "schizophrenic" those people, who failed in the process of adapting to the world of public hallucinations. Doctors try to "tame" the individual, return him to the system of group fantasy, which he tried to overcome (Laing, 1960: 62,63). Therefore, Laing considers schizophrenia not so much as pathology of behavior, but mostly as pathology of communication, a disease of human relationships. He emphasizes that any case of schizophrenia should be considered by researching not one patient, but the entire social context (in particular the family), which allows to find out the origins of pathology. The psychotic condition can be understood as an attempt to preserve a poorly structured existence. When the loss of existence is a danger to the person, the protection is that the person falls into a state of oblivion. "Neurosis is a way of avoiding oblivion by avoiding being" (Laing, 1960: 62).

Under the influence of existentialism and phenomenology, the concept of "ontological insecurity" of a person is formed, which is introduced by R. Laing in the field of the philosophy of health. His theory of the aetiology of psychosis "made it possible to perceive the social ontology of marginality, to see in this light the problem of consciousness, interpersonal communication, the role structure of a modern society and to consider the mechanisms of its functioning". 
It is difficult to notice the psychotic dimension of codependency in mentally ill people, since the experiences and natural history of the patients' lives are "frozen" by pharmacotherapy.

As R. Laing points out, being in such a "frozen" state, the patient cannot help but look broken, and his/her behaviour is illogical and unnatural. Symptoms of mental illness can be considered as "frozen" elements of certain experiences that must be completed - only then healing occurs (Laing, 2011: 78, 80, 98). By combining a systemic vision and an approach focused on subjective experiences, we can make sure that the behaviour of a psychotic patient is not irrational, instead it is rather reasonable when viewed from the perspective of his/her existential position, that is, a certain survival strategy.

\section{Ontological insecurity in the family systems theory}

There are many similarities between the roles assigned to individuals in the family, and their feelings and perceptions of themselves. "Getting in and out of the role when talking to a neighbour is as easy as taking off and putting on a raincoat. While changing one's role in own family is more like a desperate attempt to free oneself from a straitjacket", - noted psychotherapist Z. Moreno (Moreno, 1987: 38). It is about the distortion of human experience and the formation of codependency under the influence of certain family systems (in particular, schizophrenic or alcoholic ones) or close "unreal" relationships. The relations that give rise to codependency have been examined in various ways by R. Laing (Laing, 2011), G. Bateson (Bateson \& Bateson, 1987) and M. Bowen (Handbook, 2019). The cause of interdependence as a distortion of individual experience can be a specific external strategy of the family.

Bateson's theory of schizophrenia ("double bind") best describes communication patterns in families of diagnosed schizophrenics. There is a child in a "double bind" situation, who receives messages from his/her parents that contradict each other at the verbal and non-verbal levels and contain a risk of punishment or a threat to the emotional safety of the child. As R. Laing convinces: "The behaviour of a person who has received a psychiatric diagnosis is part of a wider network of abnormal behaviour, distorted communication structures" (Laing, 1960: 245). According to Laing, normal people make up our unreasonable society of constant wars and bloodshed. In turn, crazy people have freed themselves from the hallucinatory obligations that condition the lives of normal people and increase their aggressiveness (Laing, 1960: 245).

In his family systems theory, M. Bowen develops the concepts of differentiation of self in the family, emotional triangle, nuclear family emotional system, family projection process, multigenerational transmission process, sibling position, and societal emotional process (Winek, 2010: 81). The concept of differentiated self, which is the opposite of co-dependent self, is central to the Bowen's family systems theory. Bowen uses the concept of cell differentiation as a metaphor for describing family relationships. He suggested that people who function as healthy cells achieve the highest efficiency. They consider themselves as an autonomous unit, at the same time connected with other members of a larger emotional organism. From this observation, Bowen got an idea of the scale, or continuum, of the differentiation of self, which distinguishes different (strong and weak) behavioural reactions to merging with a group, detachment from others, rigidity of communication, reactivity. A person's position on the differentiation scale can vary depending on stresses in the system of relations with others.

According to M. Bowen's family systems theory, the emotional triangle is also a system of relationships consisting of three emotionally connected individuals. The triangle is the basic emotional building block or "molecule" of all systems of human relationships, "the smallest 
stable relationship system". When tension increases, the dyad, in order to suppress the anxiety, automatically draws in a third significant person. In calm periods, all members of the triangle (consisting of sufficiently differentiated individuals) can easily change their positions, move from the position outside the triangle to its middle, and so on. As part of the dyad, one person may be less satisfied with the proximity (affinity) than the other, so he/she is more active in forming a triangle. In periods of stress, everyone inside it seeks to move outward to allow the remaining dyad to bring the struggle to an end. It is this configuration that is the basis of a "father-mother-teen" triangle. The father more often goes to the outside position, while the mother and the teenage child "fixate" on each other. If there are other children in the family, then those who are most involved in the processes inside the triangle with the parents "complete this process at a lower level of functioning than a child who is relatively free from parental care" (Handbook, 2019: 67). In families where parents have low levels of differentiation from their ancestral families, triangles can be formed in such ways as marital conflict, problems with a spouse, problems with one or more children. Basically, the object of the projection of family non-differentiation (codependency) is the eldest child in the family, the only child, a child with special needs or a child pathologically attached to one of the parents.

The early experience of children in the communication systems of alcoholic parents forms in them a special inner world of emotions, which leads to codependency and psychotization. "The experience of a child staying in a distorted family communication system forms a neurosis instead of a new, meaningful and flexible life perspective". The intra-family role of a "sacrificial lamb", a "rebel" is transferred to other relations and groups. as noted by R. Baron and D. Richardson (Baron \& Richardson, 1994: 20).

The first attempts to understand the family as a system that generates the distorted experience of its members were made, as already noted, by the American researcher M. Bowen. The basis of the Bowen Family Systems Theory is the position of the human emotional system, which functions without reaching the surface of consciousness. Such manifestations of feelings as sadness, joy, anger, frustration are usually recognized, but they can also manifest themselves at a deeper level: in the form of physiological symptoms or disturbances in relationships. Psychotherapists schooled in M. Bowen's theory define psychological, somatic or social symptoms as a manifestation of the "emotional process", which underlies them and has been formed in complex family relationships for many generations. Family therapy, based on Bowen's theory, aims at increasing the level of differentiation of the self in the client's emotional system, leading to a decrease in the manifestations of somatic, psychological or social symptoms.

\section{Constructive psychotherapy with ontological insecurity in the family}

Structural psychotherapy also works with the problem of ontological insecurity. S. Minukhin's structural therapy was based on certain ideas about the structure and organization of the family. In the $1950 \mathrm{~s}$, the focus was on the individual unit, that is, work with an individual family member. J. Haley found that the rapid changes achieved by an individual unbalanced his/her entire family. In the $1960 \mathrm{~s}$, a "double communicative unit" was in the focus of researchers' attention, which is related to the specifics of painstaking and lengthy work of a psychotherapist with a patient (Bateson, Jackson, Haley \& Weakland, 1963). In the 70s, interest in "dynamic and short-term/brief" psychotherapy began to grow in American society. Haley's strategic approach that was formed at that time began to be thought of as authoritarian, openly addressing the restructuring of control and power in the family, which determined the psychopathological symptom. 
Psychotherapists under the influence of V. Satir (Satir,1983) (who emphasized in the work of a psychotherapist the need to help the family in establishing truly close, love-filled relationships) considered the strategic method to be formal, fenced off from the emotional bond on which the family holds. However, the transformation of the strategic approach in family psychotherapy continued. Its main successor was M.S. Palazzoli who believed that each member of the family has his/her own strategic line, own choice, own idea of therapy (Palazzoli, Boscolo, Cecchin \& Prata, 1978). The Milanese method (the method of Palazzoli and colleagues), which was outlined in the book "Paradox and Counterparadox", has become world famous among family psychotherapists (Sluzki, 2004).

In the 1970-80s, family psychotherapy was embraced by the process of changing orientation from psychoanalysis and behaviourism to a more cognitive model. Since its inception, family therapy has focused more on changing the way people behave than on changing their way of thinking, but later it made a turn to the "theory of stories" (Hapon \& Vovk, 2020: 9). People organize the world in short series of meanings, or "stories," "topics" that resemble time flows, arise and transform in the dialogue on which the therapeutic conversation is built. Social constructivism as a guideline for modern psychotherapy is a way to understand: everything that is described by a psychotherapist is created by him/her. Therefore, the psychotherapist is especially careful in assuming the responsibility of an "expert" (Hapon \& Vovk, 2020: 9). Rejection of "game" with the family, instructions, and orders is a refusal to fight.

Therapy here is a conversation of a special nature. As an image of the therapeutic process, a "conversation" is more accurate than a "game". The conversation equalizes, it does not pursue any specific goal, and no one loses or wins in it. The psychotherapeutic process includes values from the psychotherapist's self, and never from the "objective truth". Psychotherapy unfolds as a dialogue with the family, rather than as the intervention of "social engineers" who bring the values of individual family experiences in line with social stereotypes. Therefore, the distortion of individual experience under the influence of negative family systems or relationships is overcome by various psychotherapeutic areas, and for the new generation of psychotherapists the task of psychotherapeutic changes in the pattern of codependency as a consequence of traumatic individual experience in family systems remains no less dramatic.

\section{Conclusions}

Optimal educational options for solving the problem of co-dependence lie in the implementation of programs by psychological services of educational institutions, which offer free assistance (trainings, consultations) with elements of individual and family therapy to participants of the educational system. These are important different and effective educational approaches for family members to understand the patterns of their interaction. The attainment of ontological security is possible with help of psychotherapeutic activities, provided by psychological services of educational institutions. Only with help of these structural units of educational institutions it is possible to restore the personal boundaries of a person, awareness of family role differentiation, improvement of family communication and interaction. All this work, done by psychological services of educational institutions will allow to take significant steps towards harmonization of relationship of person and social world, will enhance the quality of educational process in institutions. Finding the ontological security of the student's personality is possible within the training courses (for example, "Person in society", "Helping others", "Psychology of harmonious relationships", etc.), in line with counseling and training of psychological services of universities, all educational institutions. 
The problem of interdependence as a marker of loss of ontological security within the distorted communication system of the family is important for the modern educational system, in particular for socio-psychological science and psychological practice, and requires consideration of psychological mechanisms of distorted family systems and psychological consequences of interdependent communication and interaction.

\section{References}

Baron, R. A., Richardson, D. R. (1994). Hunan aggression. New York: Plenum Press.

Bateson, G., Bateson, M. (1987). Angels Fear: Towards an epistemology of the sacred. Toronto: Bantam Books.

Bateson, G., Jackson, D. D., Haley, J. \& Weakland, J. (1963). Toward a Theory of Schizophrenia. In N. J. Smelser \& W. T. Smelser (Eds.). Personality and social systems. pp. 172-187). John Wiley \& Sons Inc. DOI:10.1037/11302-016

Giddens, A. (1999). Runaway World: How Globalization is Reshaping Our Lives. Brunner-Routledge.

Handbook of Bowen Family Systems Theory and Research Methods: A Systems Model for Family Research (2019). Edition, Kindle Edition by Mignonette N. Keller (Ed.), R. J. Noone. London: Routledge.

Hapon N. P., Vovk A. O. (2020). Codependency in family systems with distorted communication patterns and their manifestation in an individual's social behaviour. Personality in society: psychological mechanisms of activity; collective monograph; N. P. Hapon, S. L. Hrabovska, N. V. Hrebin., etc. Lviv-Toruń : Liha-Pres. 1-17. DOI:10.36059/978-966-397-209-1/1-16

Laing, R. D. (1960). The Divided Self: An Existential Study in Sanity and Madness. Harmondsworth: Penguin.

Laing, R. D. (2011). The Politics of the Family. Toronto: Press.

Laing, R. D. (1985). Wisdom, Madness and Folly: The Making of a Psychiatrist 1927-1957. London: Macmillan.

Palazzoli, M. S., Boscolo, L., Cecchin, G., Prata, G. (1978) Paradox And Counterparadox: A New Model In The Therapy Of The Family In Schizophrenic Transaction. N.Y.: Publisher: Jason Aronson.

Satir, V. (1983). Conjoint family therapy Palo Alto, CA: Science and Behavior Books.

Sluzki, C. E. (2004). In memoriam: Mara Selvini-Palazzoli, M.D. (1916-1999). Family Process. 38. pp. 391-398. DOI:10.1111/j.1545-5300.1999.00391

Winek, J. L. (2010) A Review of "Systemic Family Therapy: From Theory to Practice. Thousand Oaks, CA: Sage.

Young, J. (2007). The Vertigo of Late Modernity. London: Sage. 